\title{
The General Overview and Molecular Pathogenesis of Pancreatic Cancer
}

\author{
Zane Simtniece*, Andrejs Vanags*, Ilze Strumfa*, Janis Gardovskis** \\ *Department of Pathology, Riga Stradins University, Riga, Latvia \\ **Department of Surgery, Riga Stradins University, Riga, Latvia
}

\begin{abstract}
Summary
Pancreatic cancer is one of the most aggressive tumours. It is characterized by poor prognosis and short survival after potentially radically surgical treatment. The problem of pancreatic cancer is aggravated by mostly delayed diagnostics and a high number of metastatic cases of pancreatic cancer. The solution could be to find target molecules for early diagnostics and treatment or to find convincing aetiological factors or the most important risk factors. In this study we summarize recently published data of pancreatic cancer development, morphological changes, the pre-neoplastic lesions and the molecular pathogenesis of pancreatic cancer, which can help to find specific molecules for tumour detection, tumour progression and treatment.
\end{abstract}

Key words: Pancreatic cancer, pancreatic carcinogenesis, molecular markers.

\section{INTRODUCTION}

I. The general overview of pancreatic cancer

Pancreatic cancer (PC) is one of the deadliest human malignant tumours. In 2012, there were 103773 new PC cases in Europe and 43920 in the United States of America (USA). During the same year, the number of PC-caused death cases reached 104463 in Europe and 37390 in the USA. Among all malignant tumours excluding non-melanoma skin cancer, pancreatic cancer assumes the 8th place in Europe and the 10th place in the USA by incidence versus the 4th place both in Europe and the USA by the PC caused death rate $(4,25)$. Pancreatic ductal adenocarcinoma (PDAC), characterised by particularly poor prognosis, constitutes $85-90 \%$ of pancreatic neoplasias (9). Radical surgical intervention is the most effective treatment for the PDAC. However, it is applicable only in $14.2-15 \%$ of patients $(2,16)$. The median survival after the surgical resection of PDAC ranges 13.6 - 21 months and 5-year survival rate is $14.6-16 \%(2,5)$. If the primary tumour is unresectable, the 5-year survival rate drops to $0.6-3.8 \%$ according to the cancer stage (1). Such a poor prognosis of the PC is related to its retroperitoneal localisation and asymptomatic progression in the early stages (10). Most frequent symptoms that are noted in PC patients are abdominal pain, loss of weight, jaundice, loss of appetite and nausea, but these symptoms are nonspecific. The differential diagnosis is wide, including many other abdominal pathologies, for example, abdominal aortic aneurysm, bile duct diseases and other gastrointestinal pathologies. The anatomical localisation of the pancreas also embarrasses the diagnostics of PC (8). The mean size of the PDAC at the time of diagnosis is $3.7 \mathrm{~cm} \mathrm{(26).}$ PDAC of the pancreatic body or tail are larger reaching the mean diameter of $6.22 \mathrm{~cm}(21)$. If the tumour size is less than $10 \mathrm{~mm}$ and the patient has no lymph node or other metastases, the 5 -year survival rate is $75 \%$, but even set of several diagnostic visualisation methods including computed tomography (CT), ultrasonography (US), magnetic resonance imaging (MRI), endoscopic retrograde cholangiopancreatography (ERCP) and endoscopic ultrasonography (EUS) can fail to detect the tumour because of its small size (8). Poor prognostic factors include moderate to high histological grade, metastases in lymph nodes and positive resection line $(6,11,26)$. To investigate the aggressiveness of PC and to improve diagnostic and therapeutic methods, mostly the PC research aims to establish and to define more precisely risk factors and pathophysiological and molecular deviations caused by the genetic and epigenetic dysregulation.

At present, epidemiological studies have identified family history, age, chronic pancreatitis, smoking, adiposity and diabetes mellitus (DM) as the most important risk factors for PC (8). The blood relatives within so-called hereditary PC families are included in the high risk group comprising about $5 \%$ of all PC patients. The hereditary PC is observed within several genetic syndromes as Lynch syndrome II variant (mutation in MLH1, MSH2, MSH6 and PMS2 genes), cystic fibrosis (mutation in CFTR gene), familial atypical multiple mole melanoma (somatic inactivation of pl6), Peutz-Jeghers syndrome (mutation in the STK11 tumour suppressor gene) and hereditary breast and ovarian cancer (mutation in the $B R C A 2$ and BRCA1 genes). The risk of PC is increased also in first-degree relatives of PC patients $(8,12)$.

PC incidence is highest in $55-80$-year-old patients: $19.1 \%$ of new cases occur in 55 - 64-year-old patients, $25.6 \%$ in those aged $65-74$ years, but $30 \%$ in those aged $75-84$ years (8).

Alcohol consumption and smoking are best known as the causes of the acute pancreatitis, but if there are several episodes, recurrent pancreatitis can develop, leading to chronic inflammation and fibrosis (15). 
Smokers have about 2-fold excess risk of PC. It is hard to evaluate selective alcohol-related risk of PC because usually alcohol is combined with smoking. Some of the studies regarding non-smoker population show that the risk of the development of PC is higher if $3-9$ drinks per day are consumed (30).

Central and overall obesity is associated with 1.4 2 -fold higher PC risk. The development of PC has been associated with perturbed energy balance, chronic inflammation, insulin resistance, hyperinsulinemia, oxidative stress, dysregulation of adipokinase secretion, glucose intolerance and DM (15). Following-up recently diagnosed DM patients for 6 years, PC develops in $0.5 \%$ of cases. More often PC is the cause of the DM. Thus, DM can be an important PC symptom, especially in lowweight patients, middle-aged patients, or older patients without diabetes mellitus in family history (30). Some studies have showed that DM in initial stage is observed in $45-65 \%$ of PC patients (18).

Smoking, adiposity, DM, chronic alcohol consumption and chronic pancreatitis, all recognised as risk factors of PC, cause constant overproduction of inflammatory mediators that result in genome damage, altered gene expression and induction of oncogenic signalling pathways. As a result, pancreatic intraepithelial neoplasia (PanIN) develops (15). First stage of PanIN (PanIN-1) has been found in $65.5 \%$ of chronic pancreatitis patients (22). Eventually this pathologic process progresses to PDAC (15).

The most effective invasive and non-invasive methods are searched for early diagnostics of PC, giving preference for non-invasive methods. Early identification of PC by radiologic visualisation methods mentioned before is complicated. Combination of EUS with CT or MRI can be useful, but the most effective is EUS in association with EUS-guided fine-needle aspiration $(8,29)$. Serological markers have also been searched for to ensure an early diagnosis and evaluate effectiveness of the therapy. CA19.9 is one of the most frequently used markers, mostly for the evaluation of treatment results. As it lacks specificity, CA19.9 has not been used to establish the diagnosis (8). Expression of CA19.9 is observed in PC as well as in benign conditions (hepatitis, liver cirrhosis, cholecystitis, acute cholangitis, pancreatitis, pneumonia, pleural effusion, renal failure) and other malignant tumours including colorectal, gastric, lung or ovarian carcinoma and cervical squamous cell carcinoma $(8,19)$. Only $65 \%$ of PC patients have elevated CA19.9 level, thus the sensitivity $(69-98 \%)$ and specificity (46$98 \%$ ) are low (8). Other markers have slightly higher sensitivity and specificity, for example, pancreaticassociated antigen (SPan-1), which is positive in $81.3 \%$ of PC cases and its sensitivity is $81.3 \%$ while specificity $75.6 \%$. CEACAMl has sensitivity $85 \%$ and specificity $98 \%$ but TSGF - sensitivity $91.6 \%$ and specificity $93 \%$. All these markers are also positive in chronic pancreatitis and non-pancreatic benign conditions (8).

The overall neoplastic transformation of pancreatic ducts includes complex interaction between inflammation, immune reactivity and accumulation of the genetic events.

\section{Pancreatic carcinogenesis Precursors to pancreatic cancer}

There are three pre-invasive precursor lesions of PC: pancreatic intraepithelial neoplasias (PanINs), mucinous cystic neoplasms (MCNs), and intraductal papillary mucinous neoplasms (IPMNs).

Pancreatic intraepithelial neoplasias (PanINs) involve small terminal pancreatic ducts $(<5 \mathrm{~mm})$. There are three levels of PanIN depending on the grade of atypia (Figure 1). PanIN-1 is characterised by change of normal ductal epithelium to high columnar epithelium with intracellular mucin. There are two kinds of PanIN-1. In PanIN-1A epithelial layer is flat, but in PanIN-1B it is papillary. PanIN-2 is characterised by more remarkable cytologic atypia and nuclear crowding. PanIN-3 is characterised by extensive nuclear crowding and atypia, pseudopapillary growth, mitotic figures and intraluminal necrosis $(13,27)$. Because of the cellular atypia, PanIN-3 has been considered as carcinoma in situ which progresses into invasive adenocarcinoma (27).

Mucinous cystic neoplasm (MCN) is characterised by cystic architecture, mucin-producing epithelium and densely organised spindle-shaped cells under the epithelium. The grouping of stroma cells under the neoplastic epithelium is called "ovarian-type" stroma and it is an important diagnostic parameter. Similarly to PanIN, MCN is divided in three grades by dysplasia. Low grade dysplasia is characterised only by mild damage of cells, but still uniform nuclei. High grade dysplasia is characterised by a significant architectural and cellular atypia which is considered as a mucinous cystic carcinoma (27).

Intraductal papillary mucinous neoplasms (IPMNs) are non-invasive, mucin producing, more often papillary neoplasias that expand from the main pancreatic duct or branches of it with various degree of the duct dilation. IPMNs are also classified into 3 grades of dysplasia and the highest one is considered an intraductal papillary mucinous carcinoma (27).

All three of the pre-invasive precursors can progress to PC. One third of the MCNs and IPMNs are associated with the development of invasive carcinoma, but PC mostly stems from the PanIN $(13,27)$. 

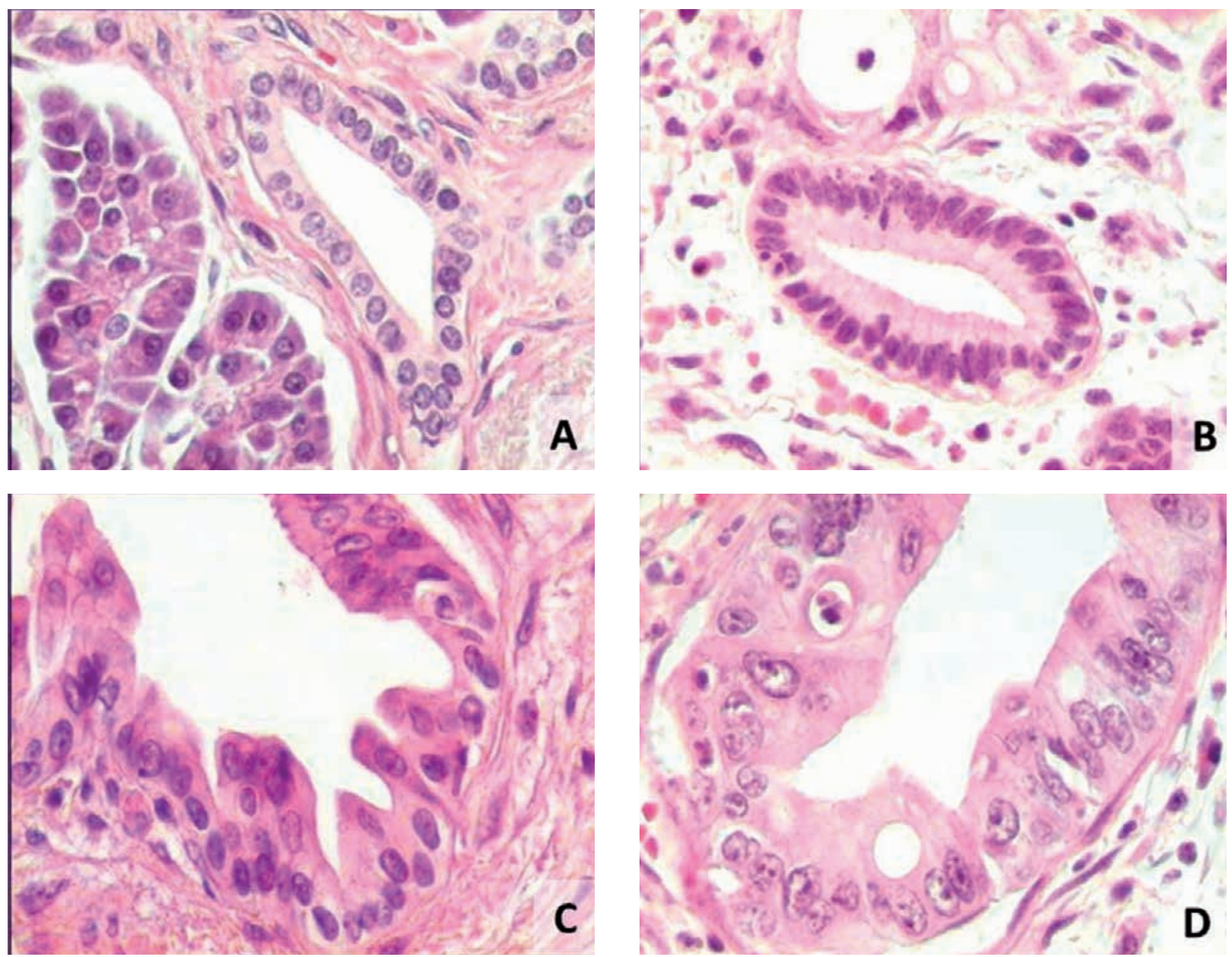

Fig. 1. Normal duct and pancreatic intraepithelial neoplasias (PanINs) in the pancreas. A, Normal pancreatic duct. Haematoxylin-eosin (HE), original magnification (OM) 400x. B, Pancreatic duct with PanIN-1A lesion. HE, OM 400x. C, Pancreatic duct with PanIN-2 lesion. HE, OM 400x. D, Pancreatic duct with PanIN-3 lesion. HE, OM 400x

\section{Molecular pathology of pancreatic cancer through genetic and epigenetic changes}

Pancreatic cancer has complex and heterogeneous molecular characteristics. In a study of Jones S. at al. 20661 protein-coding genes of 24 PC cases were analysed yielding 1562 somatic mutations, 198 separate homozygous deletions as well as regions that had undergone single-copy losses and manifested as losses of heterozygosity and 144 focal high-copy amplifications. Among this variety of gene damage in PC, the main 12 affected signalling pathways and processes were described: $K$-ras signalling, TGF- $\beta$, JNK signalling, integrin signalling, Wnt/Notch signalling, Hedgehog signalling pathway, control of $G_{1} / S$ phase transition, regulation of apoptosis, DNA damage control, small GTPase-dependent signalling, regulation of invasion and homophilic cell adhesion. There is a great diversity of affected pathways within each tumour (7). The most important altered genes are KRAS, HER-2, CDKN2A, TP53, SMAD4 and BRCA2 $(13,27)$.

\section{KRAS}

KRAS encodes a guanosine triphosphate (GTP)-binding protein which is the main mediator in several cellular processes like cell survival, proliferation and cell motility (13). Mutations of KRAS gene belong to the KRAS signalling pathway. Altogether, there are 5 detected responsible genes in KRAS signalling pathway. At least one of these genes is damaged in all $(100 \%)$ of the PC cases (7). Mutation of KRAS gene is one of the earliest genetic changes occurring already in $99 \%$ of PanIN-1 cases $(13,27)$. Frequency of activating KRAS mutations increases with the degree of dysplasia (27).

\section{CDKN2A}

CDKN2A gene mutations affect the regulation of $\mathrm{G}_{1} / \mathrm{S}$ phase transition. Altogether, nineteen altered genes have been identified in pathway of regulation of Gl/S phase transition. Again, at least one of them is altered in all $(100 \%)$ PC cases (7). Tumour suppressor gene CDKN2A is inactivated in $90 \%$ of PDAC and the changes can be detected already in PanIN-1 $(13,27)$. 
CDKN2A gene encodes the cell cycle checkpoint protein P16. P16 stops G1-S transit by binding to the cyclindependent kinases $\mathrm{Cdk} 4$ and $\mathrm{Cdk} 6$ and preventing the binding of cyclin Dl to them (27). Loss of pl6 protein expression correlates with lymphatic invasion and widespread postoperative metastases (17). Several different mechanisms can cause the loss of pl6 expression, including homozygous deletion that is responsible for $48 \%$ of pl6 inactivation cases in PC, intragenetic mutation of the second allele of the pl 6 gene (34\% of cases) and epigenetic silencing by promoter methylation $(24,27)$. Loss of pl6 protein expression is present in almost all PC cases (27). CDKN2A gene also encodes pl4/ARF and pl 2 proteins (20). Protein pl4/ ARF sequesters MDM2 that normally help to stabilize TP53 (13). Protein p12 alteration is detected in $70 \%$ of PC cases (20).

TP53

TP53 participates in the regulation of apoptosis, cell cycle progression and DNA reparation. When the DNA is altered, TP53 activates transcription of a cyclindependent kinase inhibitor p2 1 that can bind to cyclinCdk complexes, thereby arresting cell cycle in the phase G1 (Figure 2A,2B). TP53 affects transcription of pro and anti-apoptotic genes. Inactivation of TP53 prevents DNA damage control. Altogether, here are 9 detected altered genes in pathway of DNA damage control. In $83 \%$ of PC cases at least one of these genes is damaged (7). Inactivation of TP53 gene is present in about $85 \%$ of PC cases and it is a late sign that appears only in PanIN-3 (13,27). The most common mechanism of TP53 inactivation is intragenetic mutation with loss of the second allele (13). TP53 mutation frequently results in nuclear accumulation of aberrant $\mathrm{p} 53$ protein that can be identified by immunohistochemistry as a surrogate test (27). Abnormal expression of $\mathrm{p} 53$ has been found in $81.1 \%$ of PDACs and there is a significant correlation between that finding and higher tumour grade (17).

\section{SMAD4}

Alteration of SMAD4 is a part of TGF- $\beta$ signalling pathway. During activation of this pathway, binding of TGF- $\beta$ ligand to cell surface receptors induces receptor dimerization and activation. As a result $\mathrm{Smad} 2$ and Smad3 proteins get phosphorylated and form Smad4 complexes that move into the nucleus to regulate the expression of genes involved in the control of cell cycle and cell growth and differentiation. Loss of SMAD4 in PDAC results in the loss of TGF- $\beta$-induced growth inhibition (13). In TGF- $\beta$ pathway, 37 alterations of genes are detected and at least one of them invariably occurs in PC (7). Inactivation of SMAD4 itself is noted in $55 \%-60.4 \%$ of PDAC cases and is caused by homozygous deletion or intragenetic mutation with the loss of the second allele $(13,17)$. Loss of expression of protein Smad4/Dpc4 is present in high-grade PanINs as a late event (27).

There is a significant correlation between the loss of TGF- $\beta$-induced growth inhibition and tumour size, invasion in lymph vessels and metastases in lymph nodes (17). Another important PC characteristics that develops through TGF- $\beta$ signalling pathway, is epithelial-to-mesenchymal transition (EMT). During EMT, epithelial cells change the phenotype: cells that had tight intercellular junctions and clear basal-apical polarity turn into spindle cells that are able to migrate and express mesenchymal markers, for example, vimentin, fibronectin and $\mathrm{N}$-cadherin (Figure 2C). By achieving mesenchymal phenotype, cells lose ability to express adhesion molecule E-cadherin. In general, EMT in tumours causes elevated invasion, angiogenesis, metastatic activity, chemotherapy resistance and formation of cancer stem cell population (10). In EMT, increased expression of Snail (transcriptional factor of Snail family) is established, leading to elevated expression of membrane type 1-matrix metalloproteinase (MT1MMP) and higher invasion of cells (10). However, EMT is regulated also by Wnt/Notch signalling pathway.

\section{Wnt/Notch signalling pathway}

Notch ligand Jagged 1 reduces expression of E-cadherin via increased Slug (transcriptional factor of Snail family) expression and is associated with resistance of gemcitabine, and the development of the stem cell-like phenotype in PC. In Wnt/Notch signalling pathway, 29 altered genes are detected. At least one of them has been damaged in all $(100 \%)$ of PC cases (7). Experimentally, by transferring human PDAC to nude mice it was demonstrated that PC contains less than $1 \%$ of cells that have stem cell like characteristics and ability to preserve a self-renewing quality and these are CD44+/CD24+/ ESA+ (epithelial specific antigen). The expression of CD44 in PDAC is showed in Figure 2D. Tumours that are triple positive are characterised as 100-fold more tumourogenetic than unsorted cells (10).

\section{Hedhehog signalling pathway}

Hedgehog signalling has an important role in the tumour growth, EMT and resistance of gemcitabine (10). It is possible to induce cancer cell apoptosis and to block proliferation by inhibiting the Hedgehog signalling with cyclopamine, and it also induces decrease of snail expression and renewed expression of E-cadherin $(3,28)$. Nineteen genetically altered genes are included in the Hedgehog signalling pathway and again at least one mutation on this pathway is invariably present in PC (7). Expression of sonic hedgehog is increased in $70 \%$ of PDACs. It is present already in PanIN beginning from PanINl to PanIN-3 (28). 

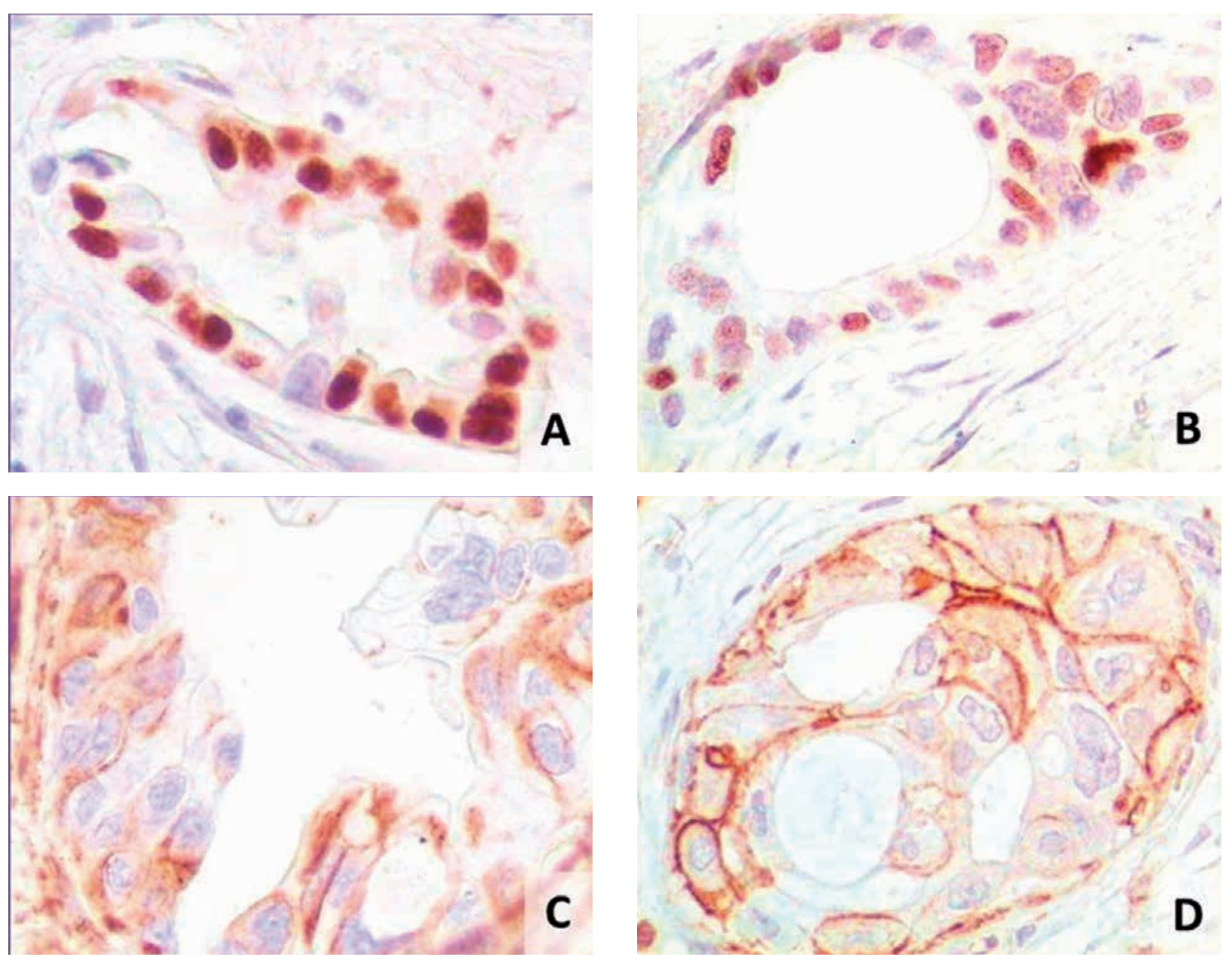

Fig. 2. The expression of immunohistochemical markers in the pancreatic ductal adenocarcinoma (PDAC). A, The expression of tumour suppressor protein p53 in PDAC. Immunoperoxidase (IP), anti-p53, original magnification $(O M) 400 x$. B, The expression of the cyclin-dependent kinase inhibitor p21 in PDAC. IP, anti-p2 1, OM 400x. C, The expression of the mesenchymal marker vimentin in PDAC. IP, antivimentin, OM 400x. D, The expression of the cell-surface glycoprotein CD44 in PDAC. IP, anti-CD44, OM 400x.

\section{Epigenetic changes}

In addition to genetic events, epigenetic processes are very important in the PC development (14). Epigenetic changes include alterations in the methylation pattern of DNA, histone modification, physical and chemical changes in chromatin structure and miRNA-mediated regulation of gene expression $(8,14)$.

DNA methylation silences gene expression. It can be inherited or develop de novo (14). Eight aberrant hypermethylated genes are found in PC contrasting to normal pancreatic cells $(14,23)$. Prevalence of methylation grows with the increase of the PanIN grade. For example, the inactivation of pl6 is an early sign of PC, but methylation of DNA is just one of the pl6 inactivation mechanisms (23).

PDAC is characterised by two main mechanisms of histone modification: histone acetylation and histone methylation (14). Acetylation (by acetyltransferases) activates expression of genes. The opposite process, deacetylation, involves histone deacetylases and can induce silencing of genes, for example, tumour suppressors or suppression of E-cadherin gene (14). Histone methylation is mediated by histone methylase and histone methyltransferases. That results in formation of gene silencing complex by regulation of aberrant polycomb protein, which includes suppression of pl6 (14).

MicroRNA (miRNA) is small (about 22 nucleotides) non-protein-coding RNAs that are involved in the posttranscriptional regulation of many genes (8). Bound miRNA controls gene expression by having a negative regulatory influence on it, and it can be manifested in three phases: inhibition of translation initiation, inhibition of translation elongation, recruitment of a deadenylase complex that destabilizes the mRNA and leads to deadenylation and degradation of mRNA 
(14). MiRNAs not only regulate expression of known protein-coding oncogenes and tumour suppressors, but also act as oncogenes (referred to as oncomirs) and tumour suppressors (8). Therefore dysfunctional regulation of miRNA - based genes is very significant in the initiation, progression and metastasis of cancer (8). It is important also in regulation of growth, proliferation, tumorigenesis, invasion, apoptosis and survival of pancreatic tumour cells and also maintaining the phenotype of stem cells $(8,10,14)$.

\section{CONCLUSIONS}

Initiation and progression of PC is a result of combination of heterogeneous and dynamic genetic and epigenetic processes. Evaluation of biomarkers expression can be informative for diagnostic purposes, estimation of the progression of illness and evaluation of the prognosis. Identification and summarization of pathogenetic impairments of each patient is an important step to personalised medicine (7).

\section{Conflict of interest: None}

\section{REFERENCES}

1. Bilimoria KY, Bentrem DJ, Ko CY, Ritchey J, Stewart AK, Winchester DP, Talamonti MS. Validation of the 6th edition AJCC Pancreatic Cancer Staging System: report from the National Cancer Database // Cancer, 2007; 1 10:738 - 744

2. Cleary SP, Gryfe R, Guindi M, Greig P, Smith L, Mackenzie R, Strasberg S, Hanna S, Taylor B, Langer B, Gallinger S. Prognostic factors in resected pancreatic adenocarcinoma: analysis of actual 5-year survivors // J Am Coll Surg, 2004; 198:722 731

3. Feldmann G, Dhara S, Fendrich V, Bedja D, Beaty R, Mullendore M, Karikari C, Alvarez H, IacobuzioDonahue C, Jimeno A, Gabrielson KL, Matsui W, Maitra A. Blockade of hedgehog signaling inhibits pancreatic cancer invasion and metastases: a new paradigm for combination therapy in solid cancers // Cancer Res, 2007; 67:2187 - 2196

4. Ferlay J, Steliarova-Foucher E, Lortet-Tieulent J, Rosso S, Coebergh JW, Comber H, Forman D, Bray F. Cancer incidence and mortality patterns in Europe: estimates for 40 countries in 2012 // Eur J Cancer, 2013; 49:1374-1403

5. Hamidov $\mathrm{Z}$, Altendorf-Hofmann A, Chen $\mathrm{Y}$, Settmacher U, Petersen I, Knösel T. Reduced expression of desmocollin 2 is an independent prognostic biomarker for shorter patients survival in pancreatic ductal adenocarcinoma // J Clin Pathol, 2011; 64:990 - 994

6. Handra-Luca A, Hong SM, Walter K, Wolfgang C, Hruban R, Goggins M. Tumour epithelial vimentin expression and outcome of pancreatic ductal adenocarcinomas // Br J Cancer, 2011; 104:1296 1302

7. Jones S, Zhang X, Parsons DW, Lin JC, Leary RJ, Angenendt P, Mankoo P, Carter H, Kamiyama H,
Jimeno A, Hong SM, Fu B, Lin MT, Calhoun ES, Kamiyama M, Walter K, Nikolskaya T, Nikolsky Y, Hartigan J, Smith DR, Hidalgo M, Leach SD, Klein AP, Jaffee EM, Goggins M, Maitra A, IacobuzioDonahue C, Eshleman JR, Kern SE, Hruban RH, Karchin R, Papadopoulos N, Parmigiani G, Vogelstein B, Velculescu VE, Kinzler KW. Core signaling pathways in human pancreatic cancers revealed by global genomic analyses // Science, 2008; $321: 1801-1806$

8. Kaur S, Baine MJ, Jain M, Sasson AR, Batra SK Early diagnosis of pancreatic cancer: challenges and new developments // Biomark Med, 2012; 6:597 _ 612

9. Kppel G, Hruban RH, Longnecker DS, Adler G, Kern SE, Partanen TJ. Tumours of the exocrine pancreas // Hamilton SR, Aaltonen LA. World Health Organization classification of tumours. Pathology and genetics of tumours of the digestive system. Lyon: IARC; $2000 ; 219-230$

10. Krantz SB, Shields MA, Dangi-Garimella S, Munshi HG, Bentrem DJ. Contribution of epithelial-tomesenchymal transition and cancer stem cells to pancreatic cancer progression // J Surg Res, 2012; 173:105- 112

11. Lim JE, Chien MW, Earle CC. Prognostic factors following curative resection for pancreatic adenocarcinoma: a population-based, linked database analysis of 396 patients // Ann Surg, 2003; 237:74-85

12. Lynch HT, Brand RE, Deters CA, Shaw TG, Lynch JF. Hereditary pancreatic cancer // Pancreatology, $2001 ; 1: 466-471$

13. Macgregor-Das AM, Iacobuzio-Donahue CA. Molecular pathways in pancreatic carcinogenesis // J Surg Oncol, 2013; 107:8 - 14

14. McCleary-Wheeler AL, Lomberk GA, Weiss FU, Schneider G, Fabbri M, Poshusta TL, Dusetti NJ, Baumgart S, Iovanna JL, Ellenrieder V, Urrutia R, Fernandez-Zapico ME. Insights into the epigenetic mechanisms controlling pancreatic carcinogenesis // Cancer Lett, 2013; 328:212 - 221

15. Momi N, Kaur S, Krishn SR, Batra SK. Discovering the route from inflammation to pancreatic cancer // Minerva Gastroenterol Dietol, 2012; 58:283 - 297

16. Niederhuber JE, Brennan MF, Menck HR. The National Cancer Data Base report on pancreatic cancer // Cancer, 1995; 76:1671 - 1677

17. Oshima M, Okano K, Muraki S, Haba R, Maeba T, Suzuki Y, Yachida S. Immunohistochemically detected expression of 3 major genes (CDKN2A/p16, TP53, and SMAD4/DPC4) strongly predicts survival in patients with resectable pancreatic cancer // Ann Surg, 2013; 258:336 - 346

18. Pannala R, Basu A, Petersen GM, Chari ST. Newonset diabetes: a potential clue to the early diagnosis of pancreatic cancer // Lancet Oncol, 2009; 10:88 95

19. Pavai S, Yap SF. The clinical significance of elevated levels of serum CA 19-9 // Med J Malaysia, 2003; 58:667 - 672 
20. Poi MJ, Knobloch TJ, Yuan C, Tsai MD, Weghorst CM, Li J. Evidence that P12, a specific variant of Pl6(INK4A), plays a suppressive role in human pancreatic carcinogenesis // Biochem Biophys Res Commun, 2013, 436:217- 222

21. Rohan VS, Hsu JT, Liu KH, Yeh CN, Yeh TS, Jan YY, Hwang TL. Long-term results and prognostic factors in resected pancreatic body and tail adenocarcinomas // J Gastrointest Cancer, 2013; 44:89 - 93

22. Rosty C, Geradts J, Sato N, Wilentz RE, Roberts H, Sohn T, Cameron JL, Yeo CJ, Hruban RH, Goggins M. p16 inactivation in pancreatic intraepithelial neoplasias (PanINs) arising in patients with chronic pancreatitis // Am J Surg Pathol, 2003; 27:1495 1501

23. Sato N, Fukushima N, Hruban RH, Goggins M. $\mathrm{CpG}$ island methylation profile of pancreatic intraepithelial neoplasia // Mod Pathol, 2008; $21: 238-244$

24. Schutte M, Hruban RH, Geradts J, Maynard R, Hilgers W, Rabindran SK, Moskaluk CA, Hahn SA, Schwarte-Waldhoff I, Schmiegel W, Baylin SB, Kern $\mathrm{SE}$, Herman JG. Abrogation of the Rb/pl6 tumorsuppressive pathway in virtually all pancreatic carcinomas // Cancer Res, 1997; 57:3126 - 3130

25. Siegel R, Naishadham D, Jemal A. Cancer statistics, 2012 // CA Cancer J Clin, 2012; 62:10 - 29
26. Simtniece Z, Strumfa I, Abolins A, Vanags A, Gardovskis J. Prognostic factors after curative resection of pancreatic ductal adenocarcinoma: a retrospective study // Journal of Cancer Therapeutics \& Research, 2012; 1:http://www. hoajonline.com/jctr/2049-7962/1/27\#

27. Takaori K, Hruban RH, Maitra A, Tanigawa N. Current topics on precursors to pancreatic cancer // Adv Med Sci, 2006; 51:23 - 30

28. Thayer SP, di Magliano MP, Heiser PW, Nielsen CM, Roberts DJ, Lauwers GY, Qi YP, Gysin S, Fernándezdel Castillo C, Yajnik V, Antoniu B, McMahon M, Warshaw AL, Hebrok M. Hedgehog is an early and late mediator of pancreatic cancer tumorigenesis // Nature, 2003; 425:851 - 856

29. Tummala P, Junaidi O, Agarwal B. Imaging of pancreatic cancer: an overview // J Gastrointest Oncol, $2011 ; 2: 168-174$

30. Yadav D, Lowenfels AB. The epidemiology of pancreatitis and pancreatic cancer // Gastroenterology, 2013; 144:1252 - 1261

Address:

Zane Simtniece

Department of Pathology,

Riga Stradins University,

Dzirciema Street 16, Riga,

LV-1007, Latvia,

E-mail: Zane.Simtniece@rsu.lv 